\title{
Study of Mechanical Properties of Heat treated AL 7075/Graphite Powder/Baggasse Ash hybrid MMCs
} Meghashree K A ${ }^{* 1}$, Puneeth $\mathrm{P}^{2}$, Madhu M G², Dr. H K Shivananda ${ }^{3}$

\author{
${ }^{*}$ P.G. Scholar, Department of Mechanical Engineering, UVCE, Bangalore, Karnataka, India \\ 2 P.G. Scholar, Department of Mechanical Engineering, UVCE, Bangalore, Karnataka, India \\ ${ }^{2}$ Lecturer, Department of Mechanical Engineering, Government Polytechnic Udupi-576104, Karnataka, India \\ 3Professor, Department of Mechanical Engineering, UVCE, Bangalore, Karnataka, India
}

\begin{abstract}
This research work investigated the influence of the graphite powder on the Mechanical behaviour of Aluminium 7075/Graphite Powder(Gr)/Bagasse Ash(BA) hybrid composite. This investigation reveals the effectiveness of incorporation of graphite powder in the composite for gaining enhancing mechanical properties. The Al7075 (Aluminium alloy 7075) reinforced with bagasse ash and graphite powder to form MMCs were investigated. The conventional liquid casting technique was used for the fabrication of the composite material and subject to T6 heat treatment. The composite was produced for different percentages of graphite powder and bagasse ash. The specimens were prepared as per ASTM standard size by turning and facing operations to conduct tensile tests, compression tests and hardness tests. The specimens for tensile and compression strength are tested using universal testing machine and for hardness they are tested using Brinell hardness testing machine. The reinforcement content was chosen as 2,4,6wt.\% of Graphite powder to identify its potential for self lubricating property under dry sliding conditions. Through the results, it is concluded that the MMC obtained has got better tensile strength, compression strength, yield strength and hardness properties when compared to non-heat-treated Al 7075 alone.
\end{abstract}

Keywords : T6 heat treatment, Al 7075, Graphite, Bagasse Ash, Ultimate Tensile Strength, Compression strength, yield strength, hardness.

\section{INTRODUCTION}

In this research paper we study the enhancement of mechanical properties of three different composition of composites, material preparation, test the specimen, results and conclusion. Traditional materials do not always provide the necessary properties under all service conditions. Composite materials is made from two or more constituent materials with significantly different physical or chemical properties; when combined it produces a material with characteristics different from the individual. Metal matrix composites (MMC's) are advanced materials resulting from a combination of two or more materials (one of which is metal and the other a non-metal) in which tailored properties are realized. Though many desirable mechanical properties are generally obtained with the fibre reinforcement, these composites exhibit an isotropic behaviour and are not easily producible by conventional techniques. MMCs reinforced with Graphite powder and Bagasse ash particulates tend to offer modest enhancement of 
properties. Among the MMCs the most metal used is aluminium reinforced with Graphite powder and Bagasse ash. Generally, aluminium is light weight, which is fore most requirement application and is less expensive than other light metals such as titanium and magnesium.

Moreover, when a reinforcement material is added to Aluminium matrix, the properties will further enhance, thereby making it a prospective material for many light weight applications. Aluminium matrix composites, a growing number of applications require the matrix properties of super alloys, titanium, copper, magnesium, or iron. Like all composites, aluminium matrix composites are not a single material but a family of materials whose stiffness, strength, density, thermal and electrical properties can be tailored to the suitable requirement. The matrix alloy, reinforcement material, volume, shape of the reinforcement, the location of the reinforcement, and the fabrication method can all be varied to achieve required properties. Regardless of variations, however, aluminium composites offer the advantage of low cost over most other MMCs. In addition, they offer an excellent thermal conductivity, high shear strength, abrasion resistance, and high-temperature operation, no flammability, minimal attack by fuels and solvents, and the ability to be formed and treated on conventional equipment. In this paper, composite materials were fabricated utilizing Aluminium as the matrix phase and Graphite powder and Bagasse ash as the reinforcement phases. The composite was produced using conventional foundry techniques.

\section{MATERIALS PROCURED}

\section{ALUMINIUM 7075 ALLOY}

Aluminum alloy 7075 is an aluminum alloy, with zinc as the primary alloying element. It is strong with strength and has good fatigue strength and average machinability. Alloy7075 is heavily utilized by the aircraft and ordnance industries because of it superior strength.



Fig. 1: Aluminum 7075 Ingots

\section{BAGASSE-ASH}

Sugarcane bagasse ash is a byproduct of sugar factories found after burning sugarcane bagasse which itself is found after the extraction of all economical sugar from sugarcane. It is an industrial waste which is used worldwide as fuel in the same sugarcane industry. These sugarcane bagasse ashes (SCBA) have been chemically, physically and miner logically characterized in order to evaluate the possibility of their use as a cement replacing material in concrete industry.

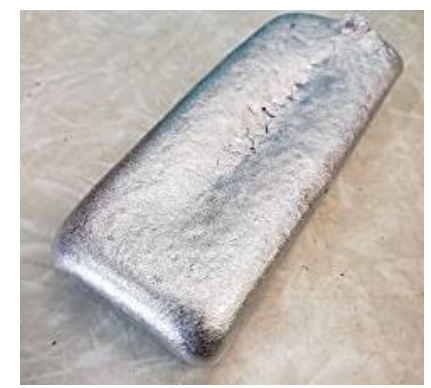

Fig. 2: Fine Bagasse Ash

\section{GRAPHITE POWDER}

Graphite is a form of elemental carbon. Graphite is used in several fields due to its electrical conductivity and chemical properties. Synthetic graphite is a manmade essence contrived by the heavy 
temperature processing of amorphous carbon materials. The types of amorphous carbon used as precursors to graphite are many and can be consequent from coal, petroleum, or natural and synthetic organic materials. In a few cases graphite can constant be manufactured by the direct precipitation of graphitic carbon (CO) from pyrolysis of a carbonaceous gas such as pyrolytic graphite (acetylene).

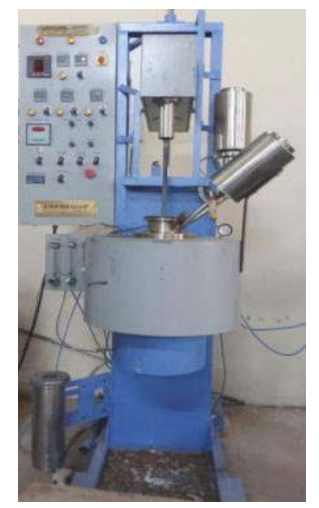

Fig.3: Graphite powder

\section{III.EXPERIMENTAL DETAILS}

Composite is picked as matrix material inferable from its wide application in numerous designing divisions including car and aviation areas. Further, this composite displays great quality and formability. Graphite exhibits the properties such as high rigidity, low thickness, low rubbing and wear resistance and high thermal conductivity. The mixture structure of composites utilized as a part of the present study is accounted for in the Table 1. Both Graphite and Al7075 combinations were acquired from M/s Fen expense Metallurgical, Bangalore, India. What's more, bagasse fiery debris is found in Mandya sugar stick industrial facility.

The composites are manufactured by following steps:

\section{Casting.}

2. Machining.

3. Testing.

\section{Casting}

The microstructure of any material is a complex function of the casting process, subsequent cooling rates. Therefore, composites fabrication is one the most challenging and difficult task. Stir casting technique of liquid metallurgy was used to prepare $\mathrm{Al}$ 7075 and $\mathrm{Al} 7075$ Hybrid composites.

Ingots of AL-7075 amalgam are set in heater and heater is warmed up to $800^{\circ} \mathrm{C}$. Ascertained amounts in weight rate are filled in the liquid AL-7075 and mixed utilizing zirconium covered spoon. All around mixture composites are filled in the die, which is as demonstrated in the fig 4 .

The melting range of $\mathrm{Al} 7075$ alloy is of $700-$ $800^{\circ} \mathrm{C}$. A known quantity of $\mathrm{Al} 7075$ ingots were loaded into the Graphite crucible of the furnace for melting. The melt was super-heated to a temperature of $800^{\circ} \mathrm{C}$ and maintained at that temperature. The molten metal was then degassed using Hexo chloro ethane tablets for about $8 \mathrm{~min}$.

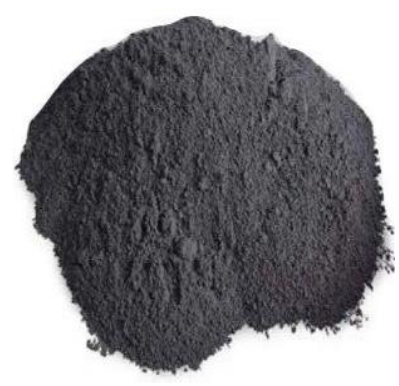

Fig. 4: Stir casting setup

As shown in Figure, the set up consists of a Coke fired furnace and a stirrer assembly, which was used to synthesize the composite.

\section{Machining}

Tensile test specimens are arranged according to the ASTM E8 principles utilizing a profoundly refined machine, which is indicated in the Fig 5. Test 
specimens are of $20 \mathrm{~mm}$ grasp width, $30 \mathrm{~mm}$ hold length, $62.5 \mathrm{~mm}$ gage length and $75 \mathrm{~mm}$ length of diminished cross area, inward measurement of $12.5 \mathrm{~mm}$ and aggregate length $155 \mathrm{~mm}$ and is indicated in the Fig 6.

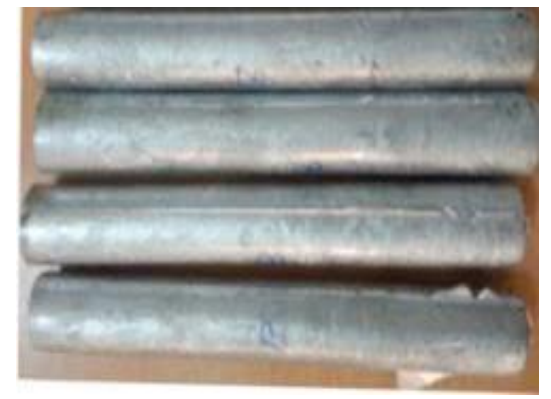

Fig 5: Casted composites

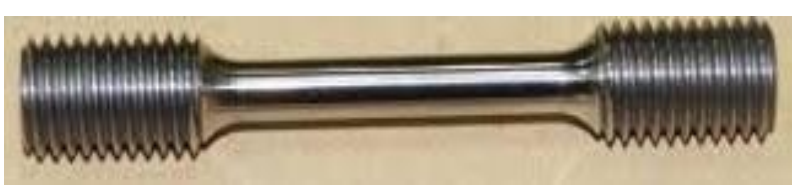

Fig 6: Tensile specimen

Compression and Hardness test specimens are prepared according to the ASTM E9 benchmark. The test specimens used are of $20 \mathrm{~mm}$ breadth and $20 \mathrm{~mm}$ length as indicated in Fig $7 \& 8$.

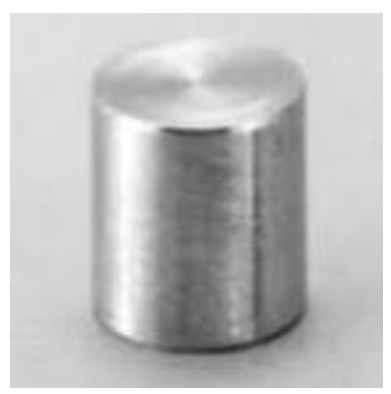

Fig 7: Compression Specimen

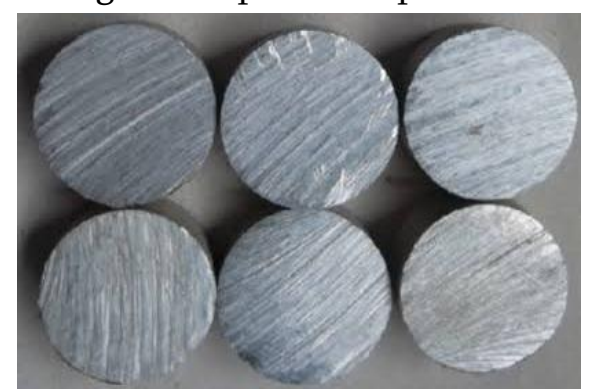

Fig 8: Hardness specimen

\section{Testing}

The test specimens are prepared as per ASTM standard size by turning and facing operations to conduct tensile tests, compression tests and hardness tests. The specimens are tested for tensile strength and compression strength as per ASTM standard E8 by using universal testing machine and hardness as per ASTM standard E10 at different loads by using Brinell hardness testing machine. Through the results, it is concluded that the MMC obtained has got better tensile strength, compression strength and hardness properties when compared to $\mathrm{Al} 7075$ alone.

\section{Heat Treatment:}

\section{T6 Heat Treat Process}

Our T6 heat treatment of cast specimens offers increase in hardness and other mechanical properties, which is often required for many applications. The T6 heat treat is a two-step process. The castings are first allowed to cool naturally and are then heated at an elevated temperature in one of our high temperature ovens. After a set period of time the castings are quickly quenched. The castings are then moved to one of our low temperature ovens for the second step of the process.

In order to develop the correct balance of mechanical properties, it was thought essential to subject the test casting to an optimized thermal treatment (viz. solution heat treatment and quenching). Test samples of suitable length were solutionized in a heat treatment furnace for a temperature of $5250 \mathrm{C} \pm 50 \mathrm{C}$ for duration of 5 hours. After solutionising the samples were immediately quenched in water kept at room temperature, stored in the tanks below the furnace. The quenching was done strictly within 15 seconds of opening the furnace door.

The specimen (as cast condition) were subjected to the following heat treatment conditions, 
- The castings are first allowed to cool naturally and are then heated at an elevated temperature of $525^{\circ} \mathrm{C}$ for 5 hrs.

- Quenching in water at a temperature of $60^{\circ} \mathrm{C}$.

Table 1: Percentage of Reinforcements.

\begin{tabular}{|c|c|c|c|}
\hline \multirow{2}{*}{ Models } & \multicolumn{3}{|c|}{ Reinforcements } \\
\cline { 2 - 4 } & $\begin{array}{c}\text { Al 7075 } \\
\text { in \% }\end{array}$ & $\begin{array}{c}\text { Graphite } \\
\text { Powder in \% }\end{array}$ & $\begin{array}{c}\text { Bagasse } \\
\text { Ash in \% }\end{array}$ \\
\hline A2G1B & 97 & 2 & 1 \\
\hline A2G2B & 96 & 2 & 2 \\
\hline A2G3B & 95 & 2 & 3 \\
\hline A4G1B & 95 & 4 & 1 \\
\hline A4G2B & 94 & 4 & 2 \\
\hline A4G3B & 93 & 4 & 3 \\
\hline A6G1B & 93 & 6 & 1 \\
\hline A6G2B & 92 & 6 & 2 \\
\hline A6G3B & 91 & 6 & 3 \\
\hline
\end{tabular}

\section{IV.EXPERIMENTAL PROCEDURE}

\section{TENSION TEST}

The ASTM E8 method covers the tension testing of metallic materials in any form at room temperature, specifically, the methods of determination of yield strength, yield point, tensile strength, elongation, and reduction of area.

\section{Testing Procedure}

1. Measure and record the tensile specimen dimensions of diameter $12.5 \mathrm{~mm}$ and gauge length $62.5 \mathrm{~mm}$ were machined from the cast specimens with gauge length of the specimens parallel to the longitudinal axis of the casing necessary to determine the cross-sectional area at its smallest point.

2. Use ink and a scribe or punch to place gage marks on the test specimen gage length of $62.5 \mathrm{~mm}$. The distance between the gage marks after the specimen is broken is used to determine the percent elongation at break. To accurately compare elongation values between tests, the gage lengths must be the same.

3. Zero the testing machine without the specimen inserted in the grips. Then install the specimen in the grips and start loading the sample. The speed of testing is generally specified in the rate of straining of the specimen. In addition, the test rate is to remain constant through yield but can then be increased when determining ultimate tensile strength and elongation at break.

4. Run the test until specimen failure or fracture. Remove the broken sample from the machine and the results will be recorded in computerized UTM.

\section{Compression Test}

Specimens are machined according to ASTM(E9) standards viz, diameter $20 \mathrm{~mm} \pm 0.1 \mathrm{~mm}$ and length $20 \mathrm{~mm} \pm 1 \mathrm{~mm}$ and test was conducted on computerized Universal testing machine. Ductility of the specimen is evacuated in term of percentage of elongation, UCS and young's modulus in terms of $\mathrm{MPa}$. The nine specimens of each compositions of cast and heattreated composites were tested and average results are noted down. Fig. 9 shows the compression specimen after the test.



Fig 9:

Compression

Specimen after the test.

Hardness Test 
The specimen is placed on the top of the table and raised it with the elevating screw, till the test sample just touched the ball.

A load of $250 \mathrm{~kg}$ is applied on the specimen for a period of 30seconds, during which indenter presses onto the specimen. The steel ball during this period moved to the position of the sample and made indentation.

The diameter of the indentation made in the specimen is recorded by the use of the micrometer microscope. The diameter of indentations is taken and the BHN is calculated. Fig 10 shows the Hardness specimen after the test.

Fig 10:

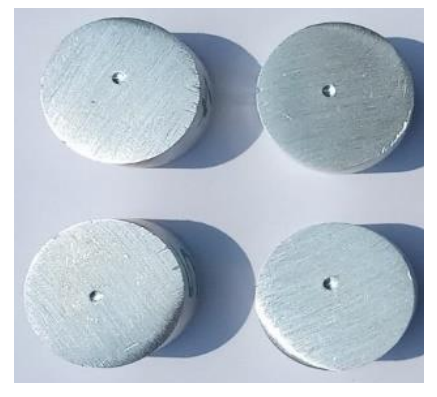

Hardness

Specimen after the test.

\section{RESULT AND DISCUSSION}

Mechanical properties like Ultimate Tensile strength, Yield strength, Ultimate Compression Strength (UCS) and Hardness are found for the developed composites of different weight $\%$ of Graphite powder and Bagasse ash in $\mathrm{Al}$ alloy 7075. The present work attempts to understand the influence of reinforcements on the matrix alloy and artificial ageing process on the $\mathrm{Al}$ alloy-based Hybrid composites compared to as cast composites.

Figs. 11-13 and Table 2 shows the effect of Graphite powder and Bagasse ash on the various mechanical properties of all alloy composites viz. Ultimate Tensile strength, Yield strength, Ultimate Compression Strength (UCS) and Hardness respectively. Each value represented is an average of nine measurements. Each value is repeatable in the sense that the individual values did not vary by more than from the mean value.

\section{Ultimate Tensile Strength}

The tensile specimens prepared in accordance with ASTM E8 were subjected to homogeneous and uniaxial tensile stresses in a Universal Testing machine.



Fig. 11: The effect of Graphite powder and Bagasse ash on the UTS of the Heat-treated Hybrid composites at the non-heat treatment condition.

\section{Effect of Graphite powder and Bagasse ash on UTS}

The factors influencing the UTS are complex and inter-related. Several variables, such as distribution of the particles/ fiber in the matrix, the mechanical properties of the matrix and the reinforcing particles/fibers and the bonding between the matrix and the reinforcement, are reported to influence the strength of discontinuously reinforced composites strongly. Also, various strengthening mechanism have been proposed to explain the improvement in strength in the case of discontinuously reinforced MMCs. They include the classical composite strengthening through 
the load transfer between the ductile alloy matrix and the hard and brittle particle reinforcement.

\section{Effect of heat treatment on Ultimate tensile strength}

Heat treatment seems to increase the UTS monotonically by significant amounts for the composites of various Graphite powder and bagasse ash contents. The maximum percentages increase in UTS of the composites is $18 \%$. Heat treatment causes the matrix to be hardened and it removes internal locked residual stresses, allowing easier movement of the dislocations. This homogenization also allows the diffusion of segregated components to produce a more uniform composition. The heat treatment is there has influenced the increase in the UTS of the composites.

\section{Compression Strength}

Compression strength of the hybrid composites specimens and of the base alloy, plotted against the Graphite powder and Bagasse ash.

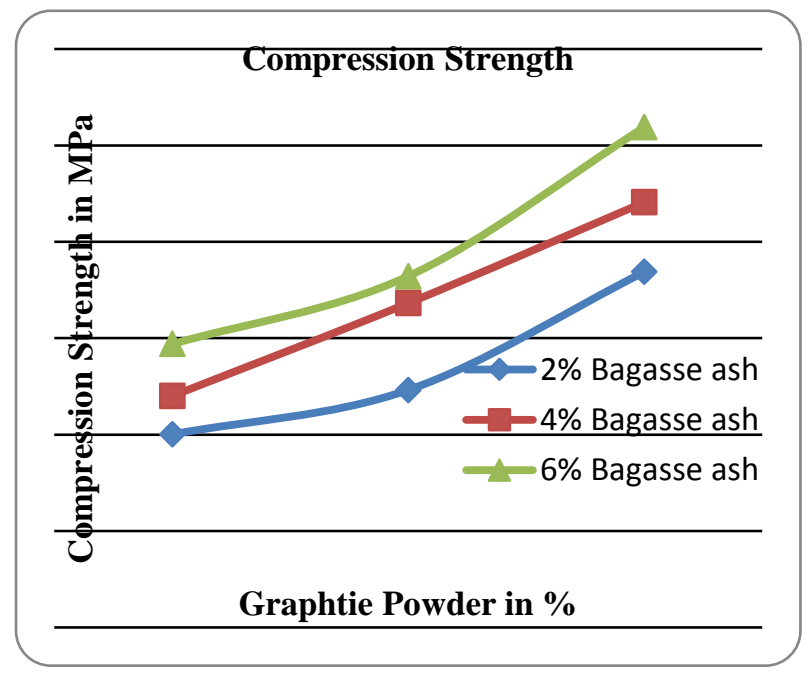

Fig. 12: The effect of Graphite powder and Bagasse ash on the Compression strength of the Heat-treated Hybrid composites at as cast condition.

\section{Effect of heat treatment on Compression strength}

Fig. 12 revealed that the heat treatment of composites has increased their compressive strength this may be due to reinforcement of microstructure that acted as barrier to dislocation of grains.

In the present investigation heat treatment and addition of Graphite powder and Bagasse ash reinforcements were found to increase compression strength. As more graphite powder and Bagasse ash particulate were added, decrease in the inter-fibre distance between hard Graphite powder caused an increase in dislocation pile-up. Moreover, improvement in compression may be due to the matrix strengthening that might have occurred following a reduction in composites grain size and the generation of a high dislocation density in the matrix as a result of difference in coefficient of thermal expansion between matrix and reinforcements. The heat treatment has increased the compressive strength by significant amounts.

\section{Hardness}

Hardness measurements were made on different sections of the as cast and heat-treated material as per ASTM E10 standards. Brinell hardness tests were carried out on samples of both cast alloy and heat treatment composites, by applying $250 \mathrm{~kg}$ for a period of 15 seconds.

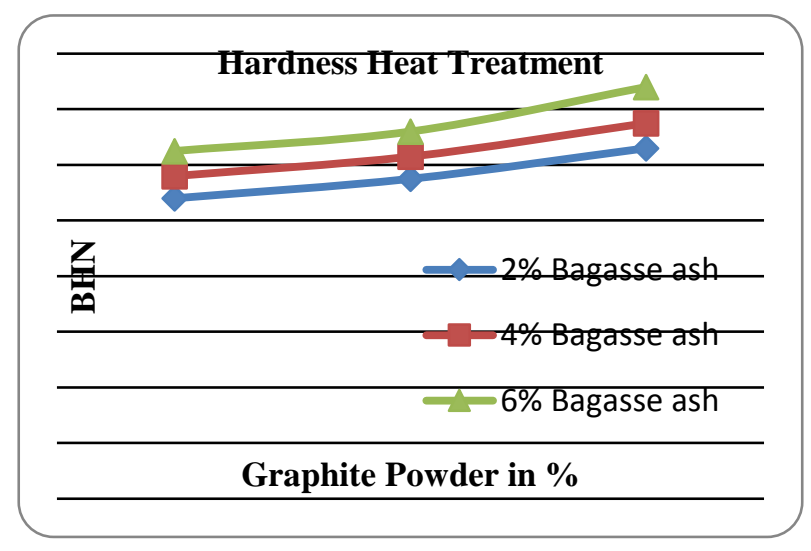

Fig. 13: The effect of Graphite powder and Bagasse ash on the Brinell Hardness of the Heat-treated Hybrid composites at as cast condition. 


\section{Effect of heat treatment on Hardness}

The hardness of the aluminum alloys is increased with the addition of Bagasse ash and Graphite powder reinforcements. Table 2 show the increase in the hardness is due to the addition of graphite powder particles and Bagasse ash, which can be attributed to the fact that the Graphite powder and Bagasse ash possess higher hardness and its presence in the matrix improves the hardness of the composite.

Table 2: Tensile strength, Compression strength, Hardness and Yield Strength of Heat-treated hybrid composites

\begin{tabular}{|c|c|c|c|c|}
\hline Model & $\begin{array}{c}\text { Tensile } \\
\text { strength } \\
\text { in } \\
\text { N/mm2 }\end{array}$ & $\begin{array}{c}\text { Compression } \\
\text { Strength in } \\
\text { N/mm2 }\end{array}$ & $\begin{array}{c}\text { Brinell } \\
\text { Hardness }\end{array}$ & $\begin{array}{c}\text { Yield } \\
\text { Stress } \\
\text { in MPa }\end{array}$ \\
\hline A2G1B & 261.8 & 950.13 & 101 & 178.7 \\
\hline A2G2B & 274.1 & 970.04 & 105 & 185.8 \\
\hline A2G3B & 296.2 & 996.97 & 114 & 199.1 \\
\hline A4G2B & 266.2 & 973.14 & 115 & 182.7 \\
\hline A4G2B & 283.5 & 1018.19 & 123 & 189.5 \\
\hline A4G3B & 298.1 & 1032.16 & 125 & 201.2 \\
\hline A6G1B & 279.4 & 1034.35 & 128 & 186.7 \\
\hline A6G2B & 292.8 & 1070.5 & 132 & 192.6 \\
\hline A6G3B & 299.4 & 1109.39 & 135 & 203.4 \\
\hline
\end{tabular}

\section{CONCLUSION}

The recently developed hybrid composites have been considered as candidate materials for applications in severe environments confronting modern technologies. Among various composites, MMCs are great practical interest. MMCs feature compositional variations from ceramic at one surface to metal at the other leads to the unique advantages of a smooth transition in thermal stress across the thickness and minimized stress concentration at the interface of dissimilar materials. As a result, such composites are rapidly finding applications in aggressive environments with steep temperature gradients such as turbine components and rockets nozzles.

The summary of the effect of particulates and fibres on the Mechanical properties of Aluminum 7075 hybrid composites like Ultimate Tensile Strength, Yield strength, Young 's modulus, ductility, Compression strength etc. are as follows.

New MMCs can be synthesized both by liquid metallurgy technique successfully with enhancedproperties using low cost Graphite Powder and Bagasse ash particulate reinforcement. Stir and permanent mold castings can be obtained with microscopically uniform distribution of particles.

> There have been notable improvements in the essential material properties with the increase in the reinforcement compositions, the properties like Ultimate Tensile strength, Yield strength, Young's modulus and Compression strength have increased significantly with the addition of Graphite powder and Bagasse ash particulate content up to $1 \%$, beyond that we observe that there is not much change in the properties.

> The addition of the reinforcements has resulted in a steady increase in the hardness. The addition of graphite powder and Bagasse ash, could have caused the increase as composites are generally hard.

The heat treatment on the hybrid composites has got very good effect on all the mechanical properties, because it has further improved the properties with appreciable amount.

\section{REFERENCES}

[1] Ravinder Kumar and Suresh Dhiman (2013). "A Study of Sliding Mechanical behaviours of Al- 
7075 Alloy and Al-7075 Hybrid Composite by Response Surface Methodology Analysis." Materials \& Design, Vol.50, pp.351-359.

[2] C. S. Ramesh. "Sand Abrasive Mechanical behaviour of Hot Forged Al 6061-TiO2 Composites", Journal of Materials Engineering and Performance, 12/23/2010 Publication

[3] Bhagat, R.B.. "Elevated-temperature mechanical properties of silicon-carbide whisker-reinforced aluminum matrix composites", Materials Science \& Engineering Publication

[4] N. Altinkok. "Use of Artificial Neural Network for Prediction of Mechanical Properties of Al2O3 Particulate-reinforced Al-Si10Mg Alloy Composites Prepared by using Stir Casting Process", Journal of Composite Materials, 07/12/2005

[5] Chen, Fei, Zongning Chen, Feng Mao, Tongmin Wang, and Zhiqiang Cao. "TiB2 reinforced aluminum based in situ composites fabricated by stir casting", Materials Science and Engineering A, 2015. Publication

[6] Sukumaran, K.. "Studies on squeeze casting of $\mathrm{Al}$ 2124 alloy and 2124-10\% SiCp metal matrix composite", Materials Science \& Engineering A, 20080825 Publication

\section{Cite this article as :}

Meghashree K A, Puneeth P, Madhu M G, Dr. H K Shivananda, "Study of Mechanical Properties of Heat treated AL 7075/Graphite Powder/Baggasse Ash hybrid MMCs", International Journal of Scientific Research in Science and Technology (IJSRST), Online ISSN : 2395-602X, Print ISSN : 2395-6011, Volume 7 Issue 1, pp. 203-211, January-February 2020. Available at doi : https://doi.org/10.32628/IJSRST207150 Journal URL : http://ijsrst.com/IJSRST207150 